
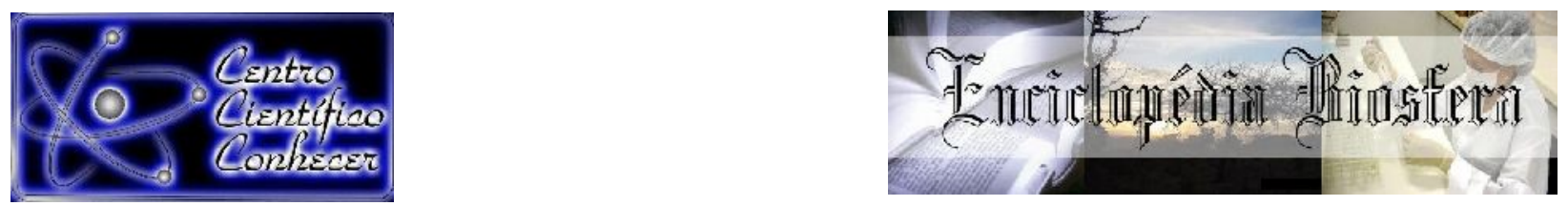

\title{
TECNOLOGIAS DIGITAIS NA EDUCAÇÃO: ABORDAGEM INTERDISCIPLINAR NA UTILIZAÇÃO DE VIDEOGAME COM SENSORES DE MOVIMENTO
}

\author{
Paulo Henrique Santana de Oliveira'; Fábio Ricardo Mizuno Lemos²; Lucas \\ Fagundes Vaz ${ }^{3}$; Maria Paulina Assis ${ }^{4}$ \\ ${ }^{1}$ Mestre em Gestão Organizacional pelo Programa de Pós-Graduação em Gestão \\ Organizacional da Universidade Federal de Goiás, Catalão-GO, Brasil. \\ (paulhsdeoliveira@gmail.com) \\ ${ }^{2}$ Doutor em Educação pela Universidade Federal de São Carlos, \\ São Carlos-SP, Brasil. \\ ${ }^{3}$ Especialista em Gestão de Tecnologia da Informação pela Universidade Candido \\ Mendes, Goiânia-GO, Brasil. \\ ${ }^{4}$ Doutora em Educação: Currículo pela Pontifícia Universidade Católica de São \\ Paulo (PUC-SP), São Paulo-SP, Brasil.
}

Recebido em: 06/04/2018 - Aprovado em: 10/06/2018 - Publicado em: 20/06/2018 DOI: 10.18677/EnciBio_2018A128

\begin{abstract}
RESUMO
A adoção de estratégias de ensino pautadas na mera exposição e reprodução de conteúdos tem colaborado para a perpetuação de uma lógica educativa centrada na "transmissão" de conhecimentos, delegando aos estudantes um papel inferior, o de depositários de informações. Em uma perspectiva democrática de educação, a qual reconhece a importância de todos os envolvidos no processo de ensino e de aprendizagem, outro horizonte de inter-relações pedagógicas precisa ser buscado. É nessa perspectiva que a utilização de metodologias ativas de forma interdisciplinar pode favorecer a efetivação de uma educação libertadora. O presente relato de experiência objetiva descrever ações realizadas utilizando tecnologias digitais na Educação, especificamente, no Ensino Técnico Integrado ao Ensino Médio de duas Instituições Federais da Região Sudeste. A partir de uma abordagem interdisciplinar entre as áreas de Linguagens e de Tecnologia da Informação, foram experienciados jogos digitais em videogame com sensores de movimento. $O$ foco das ações não se restringiu a ensinar a jogar propriamente, mas na aprendizagem colaborativa de diferentes formas de se praticar cada jogo, realizando reflexões sobre as suas consequências, tais como: apontar um "vencedor"; excluir os "perdedores"; favorecer a participação de todos; dinamizar as atuações. Tal metodologia mostrou-se apropriada para o reconhecimento de todos enquanto protagonistas e para a valorização do bem-estar coletivo.
\end{abstract}

PALAVRAS-CHAVE: educação libertadora; relato de experiência; tecnologias digitais. 


\title{
DIGITAL TECHNOLOGIES IN EDUCATION: INTERDISCIPLINARY APPROACH TO THE USE OF VIDEOGAME WITH MOTION SENSORS
}

\begin{abstract}
The adoption of teaching strategies guided by the mere exhibition and reproduction of content has contributed to the perpetuation of an educational logic centered on the "transmission" of knowledge, delegating to students a lower role, that of information repositories. In a democratic perspective of education, which recognizes the importance of all those involved in the teaching and learning process, another horizon of pedagogical interrelations needs to be sought. It is from this perspective that the use of active methodologies in an interdisciplinary way can favor the realization of a liberating education. The present experience report describes actions carried out using digital technologies in Education, specifically, in the Integrated Technical Education to Secondary Education of two Federal Institutions of the Southeast Region. From an interdisciplinary approach between the areas of Languages and Information Technology, digital video game gaming with motion sensors was experienced. The focus of actions was not limited to teaching to play properly, but in collaborative learning of different ways of practicing each game, reflecting on its consequences, such as: pointing to a "winner"; exclude the "losers"; promote the participation of all; dynamize the performances. Such methodology proved appropriate for the recognition of all as protagonists and for the appreciation of collective well-being.
\end{abstract}

KEYWORDS: liberating education; report of experience; technologies.

\section{INTRODUÇÃO}

Acreditar que na educação escolar possa se adotar uma neutralidade nas ações é ignorar que os processos educativos estão carregados de ideologia, ou seja, que há um "[...] corpus de representações e de normas que fixam e prescrevem de antemão o que se deve e como se deve pensar, agir e sentir. [...] generaliza para toda a sociedade os interesses [...] de uma classe: aquela que domina as relações sociais" (CHAUI, 2016, p. 247).

Para essa imposição, é obedecida tacitamente a "regra da competência", na qual:

[...] o emissor, o receptor e o conteúdo da mensagem, assim como a forma, o local e o tempo de sua transmissão dependem de normas prévias que decidem a respeito de quem pode falar e ouvir, o que pode ser dito e ouvido, onde e quando isso pode ser feito (CHAUI, 2016, p. 249).

Também é desconsiderar os condicionamentos do "credo capitalista" e sua ênfase na acumulação monetária (HARARI, 2017) que invade o contexto educacional. E em uma realidade em que a educação do capital impera, as atenções voltam-se mais às técnicas do que aos indivíduos ou aos processos, estando a serviço da perpetuação da ordem vigente que relega à educação o papel de reprodutora dos interesses da classe dominante (LEMOS; GONÇÁLVES JUNIOR, 2015).

Nessa visão da educação, as estratégias de ensino acabam sendo pautadas na mera exposição e reprodução de conteúdos, restando aos estudantes o papel de receptores de informações. Para Freire (2006), na visão "bancária" da educação: ENCICLOPÉDIA BIOSFERA, Centro Científico Conhecer - Goiânia, v.15 n.27; p. 1495 
[...] o educador é o sujeito, conduz os educandos à memorização mecânica do conteúdo narrado. Mais ainda, a narração os transforma em "vasilhas", em recipientes a serem "enchidos" pelo educador. Quanto mais vá "enchendo" os recipientes com seus "depósitos", tanto melhor educador será. Quanto mais se deixem docilmente "encher", tanto melhores educandos serão (p. 66).

Por outro lado, se a educação, diante dessa realidade, é concebida enquanto transformadora, enfatizará as pessoas, as experiências vividas por elas em comunidade, pois acredita-se que homens e mulheres são "[...] capazes de comparar, de valorar, de intervir, de escolher, de decidir, de romper [...] Só somos porque estamos sendo. Estar sendo é a condição, entre nós, para ser" (FREIRE, 2005, p.33).

Para Lemos e Gonçalves Junior (2015):

[...] a possibilidade de sonhar, apresentando inclusive a importância dos sonhos para a realização de uma vida significativa (que vai além dos condicionamentos), é uma realidade para os que fazem a escolha por uma perspectiva científica e de educação ampliada, que estabelece como foco central o conhecimento humanizado, preocupado com a retomada da humanidade dos indivíduos e de suas relações (p. 42).

E ao se perceber que homens e mulheres não são apenas objetos da História, mas seus sujeitos igualmente, um educador ou uma educadora humanista orientará suas ações no sentido da humanização de ambos, educador/educadoraeducando/educanda, o que exige o "pensar autêntico" ao invés da doação, da entrega do saber (FREIRE, 2005; 2006).

Para Freire (2006), a ação de educadores e educadoras:

[...] deve estar infundida da profunda crença nos homens. Crença no seu poder criador. Isso tudo exige dele que seja um companheiro dos educandos, em suas relações com estes. [...] Já não faria depósitos. Já não tentaria domesticar. Já não prescreveria. Saber com os educandos, enquanto estes soubessem com ele, seria sua tarefa. Já não estaria a serviço da desumanização. A serviço da opressão, mas a serviço da libertação (p. 71).

Essa perspectiva de educação apresenta coerência com metodologias ativas de ensino visto que seus princípios, segundo Diesel et al. (2017), podem ser sintetizados em: os/as discentes são considerados/as no centro do ensino e da aprendizagem; os/as docentes são compreendidos/as enquanto mediadores/as, facilitadores/as, ativadores/as; há a presença de trabalho em equipe, da problematização da realidade, da reflexão; busca-se o desenvolvimento da autonomia e da inovação.

Ainda de acordo com Diesel et al. (2017): 
[...] a (re)significação da sala de aula, enquanto espaço de interações entre os sujeitos históricos e o conhecimento, 0 debate, a curiosidade, o questionamento, a dúvida, a proposição e a assunção de posição resultam, sem dúvida, em protagonismo e em desenvolvimento da autonomia (p. 285).

Com a disponibilização recorrente de novos produtos tecnológicos no mercado, as ferramentas tecnológicas se configuram como possibilidades de trabalho no contexto escolar, isto porque já são realidade no cotidiano de estudantes e docentes, segundo Schwartz et al. (2017):

\begin{abstract}
Ainda não se tem claro um balanço de todos os aspectos positivos ou negativos envolvendo o uso das tecnologias, tanto na sociedade, como no âmbito educacional, devendo, ambas as facetas, ser sempre consideradas para reflexão. [...] Independentemente do julgamento sobre seu duplo caráter (positivo ou negativo), não há mais como rechaçar, ser contrário ou não perceber a necessidade de se considerar essa temática envolvendo a relação humana com as tecnologias virtuais, em todos os campos do conhecimento. Isto se torna necessário para que a apropriação destes recursos ocorra de maneira a se poder tirar o melhor proveito de suas potencialidades (p. 5-6).
\end{abstract}

Uma das ferramentas tecnológicas utilizadas no contexto educacional são os jogos virtuais, que possuem valores educativos destacados em pesquisas, como as de Gao et al. (2013) que afirmam que os jogos contribuem para o desempenho acadêmico dos estudantes, Finco et al. (2015) que apontam a ocorrência da colaboração, ocorrida de muitas maneiras diferentes, "[...] com os alunos apoiando uns aos outros ao longo de suas práticas e se tornando mais confiantes com seu desempenho no grupo" (p. 696) e Araújo et al. (2017) que ressaltam a viabilidade dos jogos enquanto ferramentas pedagógicas no processo de ensino-aprendizagem, "[...] principalmente em se tratando de conteúdos negligenciados" (p. 531).

Por considerar a necessidade apontada por Schwartz et al. (2013), de apropriação de ferramentas virtuais, buscando tirar o melhor proveito de suas potencialidades, assim como, os estudos de Gao et al. (2013), Finco et al. (2015) e Araújo et al. (2017) que ressaltam o valor educativo dos jogos virtuais, foi realizado um trabalho utilizando tecnologias digitais na Educação, tendo como pressuposto a utilização em uma perspectiva ativa, capaz de favorecer a efetivação de uma educação libertadora. Esse relato de experiência, portanto, teve o objetivo de descrever as ações realizadas, especificamente, no Ensino Técnico Integrado ao Ensino Médio de duas Instituições Federais da Região Sudeste brasileira.

\title{
MATERIAL E MÉTODOS
}

O trabalho desenvolvido utilizou uma abordagem interdisciplinar entre as áreas de Linguagens e de Tecnologia da Informação, para a experienciação de jogos digitais em videogame com sensores de movimento. Foi utilizado o videojogo Kinect Sports, do console Xbox 360 com sensor de movimento Kinect, da empresa Microsoft (MICROSOFT, 2017).

Os jogos ocorreram no segundo semestre de 2015, para três turmas de cursos técnicos integrados ao Ensino Médio de uma Instituição Federal de Ensino do 
Triângulo Mineiro, e no primeiro semestre de 2016, para duas turmas de cursos técnicos integrados ao Ensino Médio de uma Instituição Federal de Ensino da Região Central Paulista. Em cada turma, foram utilizadas quatro aulas com 50 minutos de duração.

O procedimento para a análise foi a observação assistemática e posterior registro crítico das partidas realizadas. Segundo Moresi (2003), a observação enquanto instrumento de coleta de dados é a utilização dos "[...] sentidos na obtenção de dados de determinados aspectos da realidade" (p. 29), sendo assistemática quando "[...] não tem planejamento e controle previamente elaborados" (p. 29).

\section{RESULTADOS E DISCUSSÃO}

As observações assistemáticas do processo educativo com o videojogo Kinect Sports se restringiram ao trabalho desenvolvido com as três turmas referidas anteriormente, de cursos técnicos integrados ao Ensino Médio, utilizando-se o Futebol, modo de jogo: Evento Principal, sendo os registros das partidas realizadas com as turmas, incluindo a descrição do jogo, expostos criticamente.

O Futebol é um dos seis esportes presentes no Kinect Sports (Futebol; Boliche; Atletismo; Boxe; Vôlei de Praia; Tênis de Mesa) e a proposta foi de jogá-lo de modo crítico, para superação da realidade indicada por Lemos e Gonçalves Junior (2015):

Um exemplo da ideologia da dominação envolvendo a Educação Física Escolar é a realidade do esporte ensinado nas escolas, que é o conteúdo hegemônico da área e se traduz na cópia irrefletida do esporte de competição ou de rendimento e, assim sendo, fomenta vivências de sucesso para a minoria e o fracasso ou a vivência de insucesso para a maioria (p. 51).

Depois de selecionar o esporte a ser jogado, escolhe-se entre as opções: jogar com outro jogador, jogar contra o computador ou jogar contra outro jogador. A partir desse momento de escolha foram iniciadas as discussões e decisões coletivas com os estudantes, considerando que o diálogo é, de acordo com Freire (2006): "[...] encontro dos homens para ser mais [...] não há o diálogo verdadeiro se hão há nos seus sujeitos um pensar verdadeiro. Pensar crítico. Pensar que [...] reconhece entre eles uma inquebrantável solidariedade" (p. 95).

Após reflexão junto com os estudantes sobre a opção por uma forma cooperativa ou competitiva de jogo, passou-se de uma perspectiva de adversário, para uma lógica de companheiro de equipe, escolhendo-se jogar com outro jogador. Tal entendimento tem consonância com Lemos e Gonçalves Junior (2015) que indicam na lógica competitiva:

[...] há sempre um vencedor e o derrotado terá que se esforçar mais para poder ganhar da próxima vez, o que é uma falácia pedagógica, pois auxilia a perpetuar a desigualdade e a hierarquização de pessoas, incutindo o sentimento de que o único objetivo das atividades é o seu retorno quantitativo-classificatório (p. 51).

Jogando com outro, os dois participantes passaram a integrar a mesma equipe e, durante o jogo, foram se revezando e, apesar de ainda ter como 
concorrente a equipe do console, enfatiza-se a cooperação dentro da equipe, utilizando tal opção para afirmação da perspectiva humanizada das relações humanas, sendo, portanto, coerente com um contexto educativo que pretende ser crítico, reflexivo e dialógico. Segundo Freire (2006):

\begin{abstract}
Enquanto na teoria da ação antidialógica a conquista, como sua primeira característica, implica um sujeito que, conquistando o outro, o transforma em quase "coisa", na teoria dialógica da ação, os sujeitos se encontram para a transformação do mundo em colaboração (p. 191)
\end{abstract}

Há, também, a possibilidade de alterar o nível de habilidade de quem está jogando, mudando a dificuldade do jogo. Aumentando a dificuldade, pode-se jogar nos níveis: iniciante; amador; profissional; campeão. Visando inserir todas as pessoas, pela menor exigência de conhecimento do jogo, optou-se, juntamente com os estudantes, por se jogar o nível iniciante.

Começando a partida propriamente, e vale salientar que o Kinect detecta somente duas pessoas de cada vez, após os aproximadamente quato minutos de jogo (ao tempo regulamentar, soma-se um tempo extra variável) foi realizado mais um momento de reflexão com os estudantes, sobre a necessidade de cada dupla jogar de modo contínuo todo o tempo da partida.

Em resposta a problematização, foram sugeridas e utilizadas estratégias, tais como: troca da dupla comandante das ações, a cada gol feito; o/a autor/a de cada gol saía para a entrada de outro; troca de jogadores, após determinado número de ações (gol; passe; desarme; defesa). Todas as trocas precisaram de colaboração do grupo (agilidade) para que o jogo não ficasse parando, por não detectar ninguém no espaço de jogo. Coordenando as permutas, foi como se as duas pessoas diante do Kinect permanecessem as mesmas.

Continuando o exercício crítico, dialogou-se sobre as propagandas (figura 1) presentes na "marca" do "telão", nas "placas de publicidade" ou em outros locais. A exposição comercial, de tão naturalizada no cotidiano, não foi notada por muitos estudantes, o que foi discutido, principalmente pelo acesso do público infantil aos jogos, ficando a constatação de que a sedução do marketing não poupa ninguém, iniciando a "captura" de novos consumidores desde muito cedo. Concordando com Freire (2005), "[...] é uma imoralidade [...] que se sobreponha, como se vem fazendo, aos interesses radicalmente humanos, os do mercado" (p. 100).

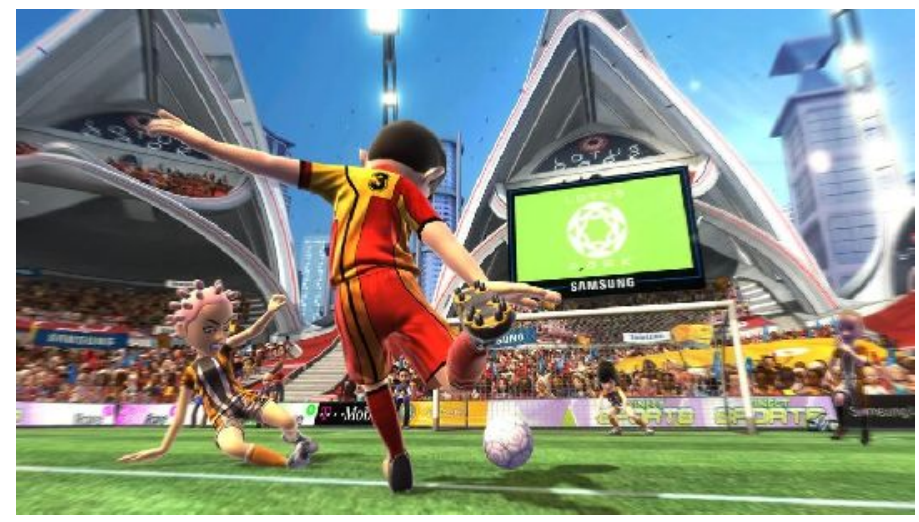

FIGURA 1. Propagandas no jogo (XBOX, 2017). 
No andamento da partida, em casos de desperdício de tempo são marcadas infrações, o que colabora para se evitar "prender" a bola por muito tempo para passar o tempo. O desperdício de tempo é punido pela marcação de Pênalti ou Chute Livre, colaborando para a não ocorrência do "corpo mole", da enrolação.

Foi debatido com os estudantes que, se o objetivo do jogo é jogar/participar, torna-se incoerente ficar parado, focando somente no resultado, afinal, é preciso se posicionar diante da racionalidade: "os fins justificam os meios". Como destacado por Freire (2005), comprometer-se eticamente é um dever: "Este é outro saber indispensável à prática docente. $\mathrm{O}$ saber da impossibilidade de desunir o ensino dos conteúdos da formação ética dos educandos" (p. 95).

No caso de faltas, que ocorrem quando a equipe do console acerta o adversário com um "carrinho", também são marcados Chutes Livres. A não possibilidade da realização de faltas (fair play obrigatório/ "jogo limpo") pelos/as estudantes foi discutida e considerada positiva.

A diversidade também foi discutida com os estudantes, com a observação dos/as personagens do jogo (mulheres, homens, diversas etnias), todos/as, jogando o mesmo jogo e participando efetivamente, ninguém com rendimento pior ou melhor. O último ponto levantado e debatido com os estudantes foi o que ocorreu no final do jogo: empate ou vitória de uma das equipes. Na vitória do computador, não há qualquer ênfase sobre a derrota (com frases como: "você perdeu"). A possibilidade de terminar em empate, ao contrário de outros jogos que exigem o desempate em cobranças de pênaltis, por exemplo, gerou a discussão da seguinte interrogação: se todos podem "ganhar", qual o problema no empate?

Entrou-se em um consenso de que em uma lógica pautada na participação, em detrimento da supervalorização do resultado, não há nenhum demérito em terminar em empate, pois nas relações construídas, como alerta Harari (2017), "Talvez não seja tão importante saber se as expectativas das pessoas são satisfeitas e se elas têm sensações agradáveis. A principal questão é se as pessoas conhecem seu verdadeiro eu" (p. 407). Um "eu" guiado pela ética universal do ser humano (solidária) ou um "eu" movido pela ética do mercado (obediente aos interesses do lucro) (FREIRE, 2005; 2006).

Finalmente, foi argumentado com os estudantes que, quando o resultado não for o esperado, sempre há a possibilidade de jogar novamente, opção disponível em qualquer placar/resultado, afinal:

A consciência do mundo e a consciência de si como ser inacabado necessariamente inscrevem o ser consciente de sua inconclusão num permanente movimento de busca. Na verdade, seria uma contradição se, inacabado e consciente do inacabamento, o ser humano não se inserisse em tal movimento (FREIRE, 2006, p. 57).

\section{CONCLUSÕES}

Com o encerramento deste trabalho, pode-se concluir que o seu objetivo foi atingido, pois as ações pautadas em uma educação libertadora foram descritas, como não poderia deixar de ser (em se tratando de um referencial progressista), de forma crítica.

Ficou visível que as atividades desenvolvidas não se restringiram a ensinar a jogar propriamente, a simplesmente reproduzir movimentos, prática muito comum em se tratando de uso de jogos virtuais, mas focaram na aprendizagem colaborativa ENCICLOPÉDIA BIOSFERA, Centro Científico Conhecer - Goiânia, v.15 n.27; p. 1500 2018 
de diferentes formas de se praticar cada partida, realizando reflexões e intervenções críticas.

Tais intervenções demonstraram ser uma significativa metodologia ativa de ensino de jogos virtuais. A partir das características observadas, é possível concluir que favoreceram a participação de todos/as, mostrando-se apropriada para o reconhecimento do direito de toda gente participar (ser protagonista), assim como, para a valorização do bem-estar coletivo (pela cooperação).

Assim, entende-se que pode servir como inspiração e parâmetro para desenvolvimento de jogos virtuais com outras turmas, não só de cursos técnicos integrados ao Ensino Médio, mas da Educação Básica em geral.

\section{REFERÊNCIAS}

ARAÚJO, J. G. E.; BATISTA, C.; LUZ MOURA, D. Exergames na educação física: uma revisão sistemática. Movimento, v. 23, n. 2, p. 529-541, abr.-jun. 2017. Disponível em: <http://seer.ufrgs.br/index.php/Movimento/article/view/65330/42068>.

CHAUI, M. S. Ideologia e educação. Educação e Pesquisa, v. 42, n. 1, p. 245-257, jan./mar. 2016. Disponível em: <http://dx.doi.org/10.1590/S151797022016420100400>. Doi: 10.1590/S1517-97022016420100400.

DIESEL, A.; BALDEZ, A. L. S.; MARTINS, S. N. Os princípios das metodologias ativas de ensino: uma abordagem teórica. Revista Thema, v. 14, n.1, p. 268-288, 2017. Disponível em: <http://dx.doi.org/10.15536/thema.14.2017.268-288.404>. Doi: 10.15536/thema.14.2017.268-288.404.

FINCO, M. D.; REATEGUI, E. B.; ZARO, M. A. Laboratório de exergames: um espaço complementar para as aulas de educação física. Movimento, v. 21, n. 3, p. 687-699, jul./set. $2015 . \quad$ Disponível em: <http://www.seer.ufrgs.br/index.php/Movimento/article/view/52435/35144>.

FREIRE, P. Pedagogia da autonomia: saberes necessários à prática educativa. 31 . ed. São Paulo: Paz e Terra, 2005.

FREIRE, P. Pedagogia do oprimido. 43. ed. São Paulo: Paz e Terra, 2006.

GAO, Z.; HANNAN, P.; XIANG, P.; STODDEN, D. F.; VALDEZ, V. E. Video gamebased exercise, Latino children's physical health, and academic achievement. American Journal of Preventive Medicine, v. 44, n. 3, p. S240-S246, mar. 2013. Disponível em: <https://doi.org/10.1016/j.amepre.2012.11.023>. Doi: 10.1016/j.amepre.2012.11.023.

HARARI, Y. N. Sapiens: uma breve história da humanidade. 22. ed. Porto Alegre: L\&PM, 2017.

LEMOS, F. R. M.; GONÇALVES JUNIOR, L. Por uma ócio-ação em motricidade escolar. In: CORREAA, D. A.; LEMOS, F. R. M.; RODRIGUES, C. Motricidade Escolar. Curitiba: CRV, 2015. p. 41-58. 
MICROSOFT. Kinect sports. Disponível em: <http://marketplace.xbox.com/ptBR/Product/Kinect-Sports/66acd000-77fe-1000-9115-d8024d5308c9>: Acesso em: $18 \mathrm{dez} .2017$.

MORESI, E. A. D. Metodologia da pesquisa. Brasília: Universidade Católica de Brasília, 2003.

SCHWARTZ, G. M.; SANTIAGO, D. R. P.; KAWAGUTI, C. N.; TAVARES, G. H.; FIGUEIREDO, J. P.; PALHARES, M. F. S.; NASCIMENTO, A. M. Apropriação das tecnologias virtuais como estratégias de intervenção no campo do lazer: os webgames adaptados. Licere, v.16, n.3, p. 1-26, set. 2013. Disponível em: $<$ https://seer.ufmg.br/index.php/licere/article/view/363>.

XBOX

Kinect

Sports.

Disponível

em:

<http://download.xbox.com/content/images/66acd000-77fe-1000-9115-

d8024d5308c9/1046/screenlg15.jpg >. Acesso em: 18 dez. 2017. 